\title{
Vocabulary to speak about touch: analysis of the discourse of electric guitar players
}

\author{
Paul Cambourian ${ }^{1, *}$, Arthur Paté ${ }^{1}$, Caroline Cance $^{2}$, Benoît Navarret ${ }^{3}$, and Jérôme Vasseur ${ }^{1}$ \\ ${ }^{1}$ Univ. Lille, CNRS, Centrale Lille, Junia/ISEN, Univ. Polytechnique Hauts-de-France, IEMN UMR 8520, \\ 41 Boulevard Vauban, 59046 Lille Cedex, France \\ ${ }^{2}$ Laboratoire Ligérien de Linguistique (LLL) UMR 7270, Site d'Orléans, 10 rue de Tours, BP 46527, 45065 Orléans Cedex 2, France \\ ${ }^{3}$ Institut de Recherche en Musicologie (IReMus) UMR 8223, UFR Musique et musicologie de la faculté des Lettres de Sorbonne \\ Université-CNRS, 2 rue de Louvois, 75002 Paris, France
}

Received 29 July 2021, Accepted 29 November 2021

\begin{abstract}
This work presents a multidisciplinary approach to vibrotactile perception, applying linguistic methods to musical acoustics. We are interested more particularly in the sense of touch as a part of the multisensory experience of playing a musical instrument. Six words and their inflections are chosen from the literature in musical acoustics dealing with vibrotactile perception: "comfort", "dynamics", "response", "feeling", "touch" and "vibration". Their use by musicians in playing situation is analyzed. The data used in this article comes from transcripts of two previous studies, conducted in French with professional guitarists natively speaking French. The linguistic analysis of the corpus is based on different features which help to categorize the utterances according to each observed parameter, namely the relationship with the sense of touch, the object that is qualified by the words under study and the implication in discourse of the interviewee. The results permit to understand the use of the six categories of words in relationship with the sense of touch, and provide perspectives to use some of these words to focus the discourse on the sense of touch in future studies.
\end{abstract}

\section{Introduction}

This work presents a multidisciplinary approach, applying linguistic methods to musical acoustics. It seems that, during perceptual tests, musicians talk more spontaneously about the sound of the instruments than about their vibrotactile perception. If the lexical field of sound is favored, this may be due to the situation of listening tests rather than playing experiences:

"By playing, violinists can experience a wider range of performance effects than the very short phrases or single notes often used in listening tests, and in this way assess any particular attribute of the instrument based on multi-modal sensory data (i.e. based on auditory and vibrotactile feedback)." [1]

The lexicon observed in the discourse of musicians, even in playing tasks [1-5], focuses to a great extent on the perception of sound and sound terms.

However, music experience is a cross-modal experience. It involves in particular the sense of touch and the interaction between the musician and the instrument, which is at the core of the action of playing an instrument [6]. The sense of touch is so important for a musician that new

*Corresponding author: paul.cambourian@junia.com interfaces for music, although they are often virtual or dematerialized, need to include vibrotactile feedback for more realistic sensations [7].

There are studies on music instruments which deal with the vibratory response of the instrument [8-13], in which only the mechanical information is measured and studied, but no perceptual measurement is carried out. Other studies couple the vibratory results with an analysis of vibrotactile feedback in perceptual tests [5, 14-17]. Even if some of them are based on words assumed to speak about the relation of the musician with the instrument and vibrotactile feedback and potentially the sense of touch, they are no demonstration of the relationship with the sense of touch. In order to be able to study the vibrotactile perception of musicians, it is necessary to use a specific vocabulary to speak about the sense of touch, identified in the musician discourse.

From the choice of an instrument to its purchase, to live performances, through their everyday musical training and practice, musicians are constantly evaluating their instruments. Scientists have aimed for decades at understanding how this expert evaluation is performed. The field of perception of musical instruments is dominated by psychophysical studies, for example to evaluate piano touch quality [13], or physical differences between two trumpets [18]. In the psychophysical paradigm, the description of the world as given by physics (in this case, acoustics) is assumed as 
the starting point, in order to test the human perception of, or sensitivity to, physical parameters. The implicit underlying assumption is that the physical parameters correspond to a psychological reality, i.e. that they are meaningful to the participants; an assumption which may or may not be true (see e.g. [19], p. 701]).

While targeting the same objectives, our approach goes in the opposite direction. We try to identify what is relevant for the participants in their everyday, expert practice, in order to eventually perform physical and acoustical studies. For this reason, we consider as important to ask first for the point of view of the musicians. Fritz and Dubois reviewed the methodology of perceptual evaluation of musical instruments in [20], and highlighted the value of playing tests combined with production of verbal data. In the same way, Fritz et al. [21], and Wollman et al. [5] conducted interviews with violinists in a playing situation. Playing situation corresponds to a more ecological ${ }^{1}$ situation. Furthermore musicians can feel vibratory signals during tests, that stimulate vibrotactile perception.

The present paper deals with an analysis of verbalizations produced in an ecological situation of guitar playing $[2,3]$. While musicians speak easily about sound and there are many studies on timbre descriptors [26-33], the vocabulary of touch does not seem to be stabilized. Studies do not demonstrate the semantic relationship to the sense of touch, and it is the main goal of this work: identify words used by musicians to speak about touch. The analysis of those words is completed with a description of the object they describe (quantification, study in context), and how they are employed, to be the most exhaustive as possible on their use in the discourse of musicians. To identify these features, we use linguistic methods and descriptors.

In this paper, six words and their inflections are chosen from the literature in musical acoustics dealing with vibrotactile perception. These six words are often assumed to be related to the sense of touch, or to describe the relation to the musical instrument. In order to check these assumptions, this paper proposes to analyze the use of these words and their inflections (which form 6 categories of words, presented in Tab. 2) by electric guitar players ${ }^{2}$ in a playing situation, and to check whether those categories of words relate to the sense of touch.

\footnotetext{
${ }^{1}$ Ecological validity aims "to ensure that the participants react in the lab, to some extent, as if they were in a natural everyday life situation" [22]. Producing an ecologically valid experiment permits an easier generalization to the real-life situation [23-25].

${ }^{2}$ The choice of the electric guitar is motivated both by the access to a corpus with transcripts of perceptual test in playing situation with verbalization; and by the fact that due to the presence of an amplifier, the sound is mainly heard through the amplifier and mechanical vibrations are transmitted by the instrument, in contact with the musician. With this separation (which does not appear with acoustic instruments), we assumed to foster the production of specific evaluations focused on the sense of touch. Moreover, the choice of studying the solid body electric guitar is motivated by its very low acoustic radiation that emphasizes the fact that most part of the sound energy comes from the amplifier (note that this might differ if using a hollow-body electric guitar).
}

We define the following working hypotheses:

- H1: the chosen categories of words may be linked to touch with some variability (speak about touch or not, with different degrees). The chosen words, even if they are linked to touch, could be used to describe different objects with different points of view (e.g. the word "feeling" may be oriented towards the sensation of the musician, and the words "response" and "dynamics" may be oriented towards the description of the guitar).

- H2: because of the mechanical behavior of the guitar and the human sensitivity, guitar players may speak differently about touch when touching and/or describing different parts of the guitar compared to when describing human body parts.

- H3: the data used in this article were produced during free playing and verbalization tests. We therefore assume that the guitar players speak about their personal experience during the test. It could be expected that the more the implication in discourse is personal and spontaneous (link to the present situation), the more the musician speaks about touch. It could be explained with the fact that vibrotactile perception is stimulated when playing, and guitarists explore the sense of touch by comparing it to their prior personal experience.

We check all these hypotheses in the present work. First, Section 2 presents the material and methods used in this study: verbal data available, selection of words related to touch, and constitution of the corpus. Then, Section 3 shows the use of linguistic features for the analysis. Section 4 presents the results of this analysis, first assessing whether the categories of words selected in Section 2 refer to the sense of touch or not. Second, results about the relationship with the sense of touch for groups of guitar parts are presented. Third, the qualified object by each category is investigated, and finally the implication in discourse of the guitar players when speaking about touch is presented. Results are then discussed in Section 5 and conclusions are drawn in Section 6 .

\section{Method}

\subsection{Perceptual tests data}

The data used in this article come from transcripts of two previous studies [2,3], made in French with professional guitarists natively speaking French ${ }^{3}$. Thirteen guitar players participated in the perceptual tests in the work of Navarret [2] and 10 participated in the work of Paté [3], for an average duration of one hour and a half per participant.

Both studies consisted in a free playing and free oral verbalization task (with similar instructions) that were

\footnotetext{
${ }^{3}$ We consider them as professionals because they make their living from guitar-related activities: concerts, lessons, reviews, etc.
} 
audio recorded and transcribed. The analysis presented here is made on these written transcripts. For each study, the players were presented with several guitars with slight modifications in their making: the guitars differed in the neck-to-body junction in the work of Navarret in 2011 $[2,34]$, and the fingerboard wood was different between the presented guitars in the work of Pate in 2013 [3]. The modifications were made unnoticeable to the eye and the guitarists were not told about any existing difference between the instruments. For both studies, the guitars (copies with slight modifications described above of the model Gibson Les Paul Junior) were connected to an amplifier (Fender Blues Junior), with the possibility to change the master volume. The guitars could be connected to a pedal effect (Ibanez Tube Screamer in [2], and Fulltone OCD III in [3]). The guitarists played seated, and were free to take and play any of the guitars they were presented, and to spend as much time as they wanted on each guitar. No pick was supplied by the researchers, therefore the guitarists played with their own pick (or with the fingers for one of them). For the work described in this article, we selected the vocabulary to analyze based on the literature in musical acoustics. The selected words are detailed in Section 2.2.

\subsection{Choice of words and categories}

As the perceptual tests with electric guitarists in [2] and [3] involved French native speakers and were conducted in French, we consider French words and categories of words in this study:

- CONFORT $^{4} /$ COMFORT, well-being provided by the instrument when playing ${ }^{5}$

- DYNAMIQUE/DYNAMiCS, defines the possible playing amplitude from the weakest to the strongest sound producible with an instrument;

- RÉPONSE/RESPONSE, the reaction of the instrument to the gesture of the musician;

- RESSENTI/FEELING, sensation and feeling expressed by the musician;

- TOUCHER/TOUCH, as a verb, to touch something is the action which creates contact between a person and an object; and as a noun, describes the sense of touch and the contact felt by the musician when playing an instrument;

- viBRATION/vibration, the mechanical displacement/ oscillation of an object;

are chosen as the categories for this study. To support the choice of these six categories, the following paragraphs present some references in the literature using the words we chose (summary presented in Tab. 1), and the detail of

\footnotetext{
${ }^{4}$ In this article, the labels of the chosen categories appear in small capitals. "Category" refers to a category of words detailed in Table 2. "Words", in italic in French and their translation between quote marks in English, correspond to the lexical forms found in the verbal productions.

${ }^{5}$ For each category, the proposed definitions just aim to help the reader to understand the global meaning of words, but are not to be considered as consensual definitions.
}

Table 1. Articles using the words chosen for this work.

\begin{tabular}{llc}
\hline Label of the category & Instrument & Reference \\
\hline CONFORT/COMFORT & Guitar & {$[2,3]$} \\
& Violin & {$[1]$} \\
\hline DYNAMIQUE/DYNAMICS & Guitar & {$[2,4]$} \\
& Violin & {$[5]$} \\
\hline RÉPONSE/RESPONSE & Guitar & {$[4]$} \\
\hline RESSENTI/FEELING & Violin & {$[1,5]$} \\
\hline TOUCHER/TOUCH & Guitar & {$[2,3]$} \\
\hline VIBRATION/VIBRATION & Violin & {$[1]$} \\
\hline & Guitar & {$[2]$} \\
\hline
\end{tabular}

words for each category (all lexical forms and inflections of the words in each category are presented in Tab. 2).

\subsubsection{COMFORT ${ }^{6}$}

The work of Paté et al. [3] provided a synthesis of the words and categories of words chosen by guitarists in [2], in order to describe and evaluate electric guitars. As the choice was completely free for the participants, it is a reflection of the words chosen by the guitarists themselves. The word confort (in French) appears in this list. Moreover, Saitis et al. [1] list violin attributes used by musicians, and the word comfort (in English) appears among the attributes describing the interaction between the player and the instrument.

\subsubsection{DYNAMICS}

The word dynamique is also present in the list of [2]. The words "dynamics" often defines the possible playing amplitude from the weakest to the strongest sound producible with an instrument, but we can imagine to transpose this definition from sound to the magnitude of vibrations. Moreover, in [4], semantic categories have been identified through discourse analysis. In this work, words within the category labeled "attack" relate to the interaction between the guitar and the musician, while words in the other categories relate to the sound directly. We therefore assumed that a word belonging to a category describing the relationship between the musician and the instrument is more likely to refer to the sense of touch. This category includes the word dynamique. "Dynamics" is "associated with both auditory and vibrotactile modalities in a balanced proportion", as demonstrated in [5].

\subsubsection{RESPONSE}

The "attack" category identified in [4] includes the word réponse. "Responsiveness" is one of the selected words assumed in [5] to be "evaluable through one or both sensory modalities under study." In the classification of violin

\footnotetext{
${ }^{6}$ From here on, the labels of the categories of words will be used in English to facilitate the reading. We insist on the fact that all the English translations in this article are suggestions to permit the understanding of this article by non-French readers and were not used by the guitarists of this study.
} 
Table 2. Words in the corpus for each category, their specific string characters (used to the semi-automatic research) and nature of words (adjective abbr. adj., noun or verb).

\begin{tabular}{|c|c|c|c|}
\hline Label of the category & Sought string in the corpus & Words in corpus & Nature \\
\hline CONFORT/COMFORT & confort & $\begin{array}{l}\text { confortable(s)/"comfortable", } \\
\text { confort }(s) / " c o m f o r t(s) ", \\
\text { inconfort/"discomfort", }\end{array}$ & $\begin{array}{l}\text { adj., } \\
\text { noun, } \\
\text { noun }\end{array}$ \\
\hline DYNAMIQUE/DYNAMICS & dynamique & dynamique/"dynamic(s)", & $\begin{array}{l}\text { adj., } \\
\text { noun }\end{array}$ \\
\hline RÉPONSE/RESPONSE & répon & $\begin{array}{l}\text { réponse(s)/"response(s)", } \\
\text { répondre/"respond" }\end{array}$ & $\begin{array}{l}\text { noun, } \\
\text { verb }\end{array}$ \\
\hline RESSENTI/FEELING & ressen & $\begin{array}{l}\text { ressenti(s)/"feeling(s)", } \\
\text { ressentir/"feel" }\end{array}$ & $\begin{array}{l}\text { noun, } \\
\text { verb }\end{array}$ \\
\hline TOUCHER/TOUCH & touch & toucher/"touch" & $\begin{array}{l}\text { noun, } \\
\text { verb }\end{array}$ \\
\hline VIBRATION/VIBRATION & vibr & $\begin{array}{l}\text { vibration(s)/"vibration(s)", } \\
\text { vibrato/"vibrato", } \\
\text { vibré/"vibrato", } \\
\text { vibrer/"vibrate" }\end{array}$ & $\begin{array}{l}\text { noun, } \\
\text { noun, } \\
\text { noun, } \\
\text { verb }\end{array}$ \\
\hline
\end{tabular}

attributes in [1], "response" is one of the most used to evaluate violins. According to Saitis ([1], Tab. II), "response" offers the capability to describe the interaction between musician and instrument and we suppose that such words can be viewed as more likely to refer to the sense of touch.

\subsubsection{FEELING}

Ressenti/"feeling" seems to be used as a general word to question/describe the sensory experience of the musician as it can be seen in the instructions of various perceptual tests [2, 3]. According to Saitis ([1], Tab. II), "feel" offers the capability to describe the interaction between musician and instrument. We can address the specific relationship to touch in the semantics of this word in our study.

\subsubsection{TOUCH}

The word toucher/"touch" makes sense as we work on the sense of touch. The word toucher appears in the list provided in [2]. Surprisingly, even with the growing literature on the sense of touch and vibratory feedback of music instruments, it seems that there is no other study with a specific attention of the word toucher.

\subsubsection{VIBRATION}

The word vibration/"vibration" has been used in instructions to provoke verbalizations about the sense of touch, as shown in experiments by Wollman et al. [5]. Moreover, verbal forms (vibrer/"vibrate") and noun forms (vibration/"vibration") are used and commented in [35], to illustrate the diversity of vibrotactile representations. Vibration is an integral part of the vocabulary associated to the sense of touch.

\subsection{Construction of corpus}

We made a semi-automatic search of the strings of characters corresponding to the different forms each category may take in French (see Tab. 2). For example, for the category COMFORT, occurrences of confort(s)/ "comfort(s)", confortable(s)/"comfortable", inconfort/ "discomfort" were sought; for the category viBRATION, the different forms vibrer/"vibrate", vibration(s)/"vibration(s)", vibrato/"vibrato", le vibré/"vibrato", etc. were sought by automatically scanning the transcripts with, for example the string "vibr".

All the occurrences considered in our corpus were formulated by guitar players. Our corpus finally contains 370 utterances. "Utterance" refers here to the combination of sentences within which at least one occurrence of a word pertains to one selected category. An utterance contains the sentence where the word occurs and the sentences before and/or after to understand the context of use of this occurrence. In the following example, the first sentence is needed to understand and complete the occurrence of réponse/"response":

Je pense que le côté moelleux, cela va être quelque chose qui ne va pas m'agresser... un sentiment de confort un petit peu, de douceur. Oui, c'est un peu plus raide comme réponse, ce qui n'est pas désagréable non plus mais je suis moins...

"I think the mellow side is going to be something that isn't going to hurt me... a little of a feeling of comfort, softness. Yes, it's a little steeper as an response, which is not unpleasant either but I am less..." (C1P2 ${ }^{7}$, RESPONSE)

For each occurrence of each word in a category, we identified a dedicated utterance, even if there could be several

\footnotetext{
7 There are two corpora of interviews. The transcriptions of the study of Navarret are gathered to form the corpus C1, and the 13 guitarists/participants are named from P1 to P13. The transcriptions of the study of Paté are gathered to form the corpus $\mathrm{C} 2$, and the 10 participants are named from $\mathrm{P} 1$ to P10. C1P2 therefore corresponds to an extract of the corpus $\mathrm{C} 1$ with the participant number 2 .
} 
Table 3. Number of occurrences (abbr. \#occ.) of each category, percentage of participants having used the words from each category (\%, abbr. \#part.), and maximum number of occurrences for a single participant (abbr. Max. \#occ. by part.).

\begin{tabular}{lccc}
\hline $\begin{array}{l}\text { Label of the } \\
\text { Category }\end{array}$ & \#occ. & \#part. $(\%)$ & $\begin{array}{r}\text { Max. \#occ. } \\
\text { by part. }\end{array}$ \\
\hline COMFORT & 35 & 56 & 7 \\
DYNAMICS & 37 & 30 & 13 \\
RESPONSE & 112 & 82 & 17 \\
FEELING & 53 & 78 & 11 \\
TOUCH & 69 & 82 & 11 \\
VIBRATION & 64 & 52 & 26 \\
\hline
\end{tabular}

occurrences in the same sentence (details of the number of utterances/occurrences in Tab. 3). Each occurrence of a word in a category is analyzed separately. We can observe that response and its occurrences represent $30 \%$ of the corpus (112 occurrences), whereas COMFORT and DYNAMICS contain respectively 35 and 37 occurrences only.

In Table 3 , we can already observe the variability between participants, for example with DYNAMICS, only $30 \%$ of participants (7 participants out of 23 ) used the words dynamique and one of the participants used the word 13 times. RESPONSE is used by most of the participants, like FEELING and тоUCH. One participant produced $41 \%$ of the occurrences of the category VIBRATION. This shows a high inter-individual variability. This variability may explain the need to deeply analyze the different words used by guitarists to speak about the sense of touch, as each guitar player may use those words differently. This work aims to clarify the various kinds of use of these words. After identifying the utterances where each category was used and creating the corpus, these utterances were analyzed with linguistic methods, with the objective of determining whether they are actually related to touch and how.

\subsection{Observed parameters}

The relationship of the selected categories of words with the sense of touch is analyzed in this article. This analysis is completed with the identification of the qualified object (what is described by each category), and the examination of the implication in discourse of musicians while talking about touch. This analysis is based on the linguistic features presented in Section 3.

The main goal of this work is to clarify the relationship of the chosen categories with the sense of touch. It is an extended and updated version of the work presented in [36]. Utterances are classified into three labels:

- Yes: when the utterance has a semantic link with touch or deals with it.

- No: when we did not find any link with touch in the utterance.

- Undefined: when the available information was not sufficient to conclude on the relationship with the sense of touch.

The analysis of utterances specifies the qualified object by each category, often assumed to be a descriptor of the musician-instrument interaction. The utterances were classified into five labels, according to their focus on:

- Guitar as sound: description of the sound of the guitar.

- Guitar as object: description of the guitar as a physical object.

- Guitar in general: description of the guitar without specific precision (sound or object).

- Interaction: description of the relation between the musician and the instrument.

- Musician: description of the feeling of the musician or of his/her behavior.

As we aimed to identify relevant words for musicians, we evaluate the implication in discourse of the musician when talking about touch. The classification of the kinds of implication in discourse is declined into three labels, in decreasing order of personal implication:

- ISE: Immediate Sensory Experience, when the discourse of the guitarist refers to tested guitars or any observations on the present situation of test.

- GOP: Generalization Of Practices, when the observations are based on personal prior experience of the guitarist.

- Doxa: it corresponds to a set of opinions received without discussion, as obvious. It is the less personal kind of implication in discourse.

\section{Analysis}

The linguistic analysis of the corpus is based on different features (word classes e.g. nouns, adjectives, verbs; personal marks, for example personal and possessive pronouns; morpho-syntactic context ${ }^{8}$, grammatical function, reference to guitar parts, reference to human body parts) which help to categorize the utterance for each observed parameter (relationship with touch, qualified object, implication in discourse). The use of each feature is detailed in this section with examples chosen in the corpus.

\subsection{Levels of context}

In this section, we distinguish three levels of context. At first a restricted context, defined by the morpho-syntactic context, at second an intermediate context corresponding to a full sentence, and finally a wide context with the entire utterance.

\subsubsection{Morpho-syntactic context}

Often, the words under study are head nouns ${ }^{9}$ of noun phrases, for example confort in confort de jeu/"playing

\footnotetext{
8 The morpho-syntactic context is used to form nominal groups or verbal groups (see [37] for details on morphosyntax in French). In this work, it refers to a restricted context, including the word under study and the associated words which form the nominal group or verbal group.

${ }^{9} \mathrm{~A}$ head noun in a group of words is considered as the core of the phrase and determines its syntactic category.
} 
comfort", or vibrations in vibrations de la table/ "soundboard's vibrations". This restricted context is named morpho-syntactic context. In the quotation below, confort de jeu/"playing comfort" refers to the relationship between the guitarist and his instrument. The word confortable/ "comfortable" in the following utterance is linked to the vibrotactile perception of the neck and the ease to play these guitars.

Sinon en terme de confort de jeu ${ }^{10}$, elles sont toutes les quatre, j'ai pas senti euh... elles sont toutes les quatre, elles me semblent toutes les quatre confortables. Je sais pas si c'est exactement les mêmes manches, si?

"Otherwise in terms of playing comfort, they are all four, I didn't feel uh... they are all four, they all seem comfortable to me. I don't know if they're exactly the same necks, are they?"

(C2P1, COMFORT)

Instead of paying only attention to isolated words, taking into account their morpho-syntactic context (restricted context) can provide details on the kind of vibration described, for example in the quote below. The soundboard's vibration is felt through the contact of the upper body of the guitarist. An interest on soundboard's vibration implies the sense of touch like in the following example.

Il y avait pour moi une différence flagrante entre la guitare verte et les deux autres, (...) je me concentrais plus sur la vibration de la table.

"There was for me a glaring difference between the green guitar and the other two, (...) I was more focused on the vibration of the soundboard."

(C1P7, VIBRATION)

Analyzing the morpho-syntactic context is a first way to get information about the qualified object in the discourse of the guitarist. In the quote above, the morpho-syntactic context shows a strong link with the sense of touch. But in some other cases, it shows that there is no reference to touch, for example in courbe de réponse/"response curve" (C1P10) which is focused on frequency response and sound perception, or harmoniques ressenties/"felt harmonics" which concerns the timbre of the instrument and also the perception of sound (C1P12). It permits an efficient distinction between utterances to assess if there is a reference to touch or not.

\subsubsection{Sentence context}

If the morpho-syntactic context is the most efficient and repeatable way to analyze and identify the qualified object, it often does not permit to conclude on the implication in discourse or the relationship with touch. The sentence context can provide this information, as in the example below:

\footnotetext{
${ }^{10}$ Occurrences of category are underlined, and specific analyzed parts are in bold font.
}

Pour définir ça, le grain c'est la matière du son, en ce qui me concerne, je ne sais pas si c'est la bonne définition, c'est comme ça que moi je la ressens.

"To define that, grain is the matter of sound, as far as I'm concerned, I don't know if that's the right definition, that's how I feel it."

(C1P12, FEELING)

In the above example, the morpho-syntactic context que moi je la ressens/"that's how I feel it" does not specify if the guitar player speaks about his prior experience or about the present task (implication in discourse) and if the use of the verb ressens/"feel" is related to the sense of touch. However, considering the whole sentence one can assume that the qualified object is the musician, because he especially explains his point of view and how he understands the concept of grain/"grain". For the implication in discourse, the morpho-syntactic context could lead to interpret the sentence as ISE with the use of present tense, but the sentence context highlights that the guitarist explains a word with his personal experience (GOP).

\subsubsection{Global utterance context}

In the wide context (whole utterance), the word under study can refer to the sense of touch, in contrast with the sense of hearing. For example, COMFORT can be used in opposition to sound, and this confirms that COMFORT is linked to vibrotactile perception and interaction:

J'ai pas vraiment fait attention au confort de la guitare, etc, j'me suis vraiment concentré plutôt sur le son et sur le... tu vois, sur le... son de la guitare.

"I didn't really pay attention to the comfort of the guitar, etc. I really focused more on the sound and the... you know, the sound of the guitar."

(C2P1, COMFORT)

In contrast, the word can refer to sound more than touch, in association with words referring to sound ("bass", "treble", "medium", "hear", etc.):

Il faut qu'il y ait du grave, il faut qu'il y ait du medium, il faut qu'il y ait des aigus, et cet équilibre, c'est un ressenti. Mais j'entends bien s'ils sont là ou s'ils ne sont pas là.

"There has to be some bass, there has to be some medium, there has to be some treble, and this balance is a feeling. But I can hear if they are here or if they are not here."

(C1P10, FEELING)

Associated with the word "dynamics", we can find information on touch through the mention of human body parts like fingers, or the use of action verbs such as "to attack" (see the example below for the use of action verbs), showing physical interaction between the player and his instrument. 
This attack is controlled by the right hand ${ }^{11}$, and the guitarist can decide to attack more or less through a gestural change, and observe the feedback of the instrument. It can be described and interpreted as a auditory feedback or a vibrotactile feedback. These two kinds of feedback are strongly linked.

Alors la dynamique d'une guitare, et la dynamique en général, pour moi, c'est le fait qu'il y a une différence énorme entre quand j'attaque et quand j'attaque pas.

$Y$ a un truc que j'aime pas trop c'est les guitares actives qui justement n'ont pas de dynamique. (...) C'est-à-dire que si j'attaque j'ai beaucoup de son, si j'attaque pas, j'ai très peu de son. La reine, pour ça, c'est encore une fois la Telecaster.

"So the dynamics of a guitar, and the dynamics in general, for me is the fact that there's a huge difference between when I attack and when I don't attack. One thing I don't like too much is active guitars that just don't have dynamics. (...) That is to say if I attack I have a lot of sound, if I don't attack, I have very little sound. The queen, for that, is once again the Telecaster."

(C2P4, DYNAMics)

By paying attention to the global context of each occurrence, we can find specific information on sound or touch (information not available with only the morpho-syntactic context) as the wide context of the utterance provides more information than the other kinds of context. Then, the analysis of the relation between the word under study with the other sentences within which it appears can help to determine the relationship with the sense of touch.

\subsection{Guitar and human body parts}

\subsubsection{Association with body parts}

There are few occurrences of parts of human body (only 51 utterances out of 370), but they provide information in relation to touch, especially on the interaction with the fingers. The body of the guitarist, where skin is the vector of touch, is in contact with the instrument (hands and fingers with neck and strings, upper human body with the body of the guitar). It is illustrated with the following utterance mentioning the category COMFORT.

La touche, euh, c'est pas si mal fait qu'ça, ça ne fait pas trop mal aux doigts. Certaines guitares neuves, euh, ils oublient de limer les barres de frettes, donc ça fait souvent très mal aux doigts. Là ça va encore, c'est assez confortable, assez facile à jouer. L'action des cordes est... pour moi me convient parfaitement.

"The fingerboard, uh, it is not that badly done, it doesn't hurt the fingers too much. Some new guitars, uh, they forget to sand the fret bars, so it often hurts the fingers a lot. That's okay again, it is quite

\footnotetext{
11 The standard situation of playing guitar considered here is left hand on neck, and right hand to excite strings. The situation is inverted in case of left-handed guitars.
}

comfortable, quite easy to play. The string action is... for me it is a perfect fit."

(C2P6, COMFORT)

The example above shows that the use of body parts like "hands" and "fingers" may refer to touch. In the following example, the use of "fingers" and "hands" allows to state that the feeling of vibration is described, with no interest to the sound description but rather to the pain felt at the top of the fingers and therefore the sense of touch. The human body part oreille/"ear" is used in opposition to the vibratory feedback, as the guitar player did not hear the sound of the guitar, but felt the vibrations produced by the instrument. The guitar player made an opposition between the sound heard in his ears and the vibration felt in his fingers (and his left hand).

Là, je sens la guitare qui vibre, dans les doigts, dans mes mains. Même si on ne l'entend plus à l'oreille, je sens que cela continue à vibrer.

"There, I feel the guitar that vibrates, in the fingers, in my hands. Even if one can't hear it in your ear anymore, I feel that it continues to vibrate."

(C1P10, viBRATION)

The use of human body parts implies in general a relationship to the sense of touch, in particular when the "fingers" or "hands" are involved.

\subsubsection{Association with guitar parts}

Guitarists mention different parts of the guitar in the description of their sensations. It has to be established whether the occurrences of guitar parts could be used to qualify the relationship with the sense of touch. The guitar players can describe guitar parts in contact with their hands and fingers, like frets and neck. Table 4 presents all the guitar parts we found in the corpus in French with a tentative English translation, classified in six groups.

The category COMFORT is often linked with guitar parts, as words to speak about vibrotactile sensations.

Le manche me semble légèrement différent. Plus en... plus en $V$, peut-être. On sent plus l'arête au milieu. Un peu moins confortable, je trouve, que la précédente. Maintenant, le... peut-être c'est l'action... il me semble que le tirant de corde n'est pas... n'est pas identique non plus.

"The neck looks slightly different to me. More in... more V-shaped, maybe. You can feel the edge more in the middle. A bit less comfortable, I find, than the previous one. Now, the... maybe it is the action... it seems to me that the gauge is not... is not the same either."

(C2P10, CONFORT)

Talking about тоUCH implies a lot of occurrences of different guitar parts (frets, wood, fingerboard, neck...), which help to assess that there is a relationship to the sense 
Table 4. Grouping of guitar parts used in the corpus in French with their English translations.

\begin{tabular}{|c|c|c|}
\hline Label of the group & French words & English translation \\
\hline $\begin{array}{l}\text { Bois } \\
\text { "Wood" }\end{array}$ & $\begin{array}{l}\text { Bois } \\
\text { Ébène } \\
\text { Érable/ } \\
\text { maple } \\
\text { Lutherie } \\
\text { Matériaux } \\
\text { Palissandre/ } \\
\text { rosewood }\end{array}$ & $\begin{array}{l}\text { Wood } \\
\text { Ebony } \\
\text { Maple } \\
\text { Lutherie } \\
\text { Materials } \\
\text { Rosewood }\end{array}$ \\
\hline $\begin{array}{l}\text { Corde } \\
\text { "String" }\end{array}$ & $\begin{array}{l}\text { Action } \\
\text { Corde } \\
\text { Diapason } \\
\text { Échelle } \\
\text { Nylon } \\
\text { Tirant }\end{array}$ & $\begin{array}{l}\text { Action } \\
\text { String } \\
\text { Scale }^{1} \\
\text { Scale } \\
\text { Nylon } \\
\text { Gauge }\end{array}$ \\
\hline $\begin{array}{l}\text { Corps } \\
\text { "Body" }\end{array}$ & $\begin{array}{l}\text { Caisse } \\
\text { Chanfrein } \\
\text { Corps } \\
\text { Planche } \\
\text { Table }\end{array}$ & $\begin{array}{l}\text { Body } \\
\text { Forearm } \\
\text { chamfer } \\
\text { Body } \\
\text { Board } \\
\text { Soundboard }\end{array}$ \\
\hline $\begin{array}{l}\text { Électronique } \\
\text { "Electronics" }\end{array}$ & $\begin{array}{l}\text { Ampli } \\
\text { Bobinage } \\
\text { Double } \\
\text { Micro } \\
\text { Pédale } \\
\text { Plot } \\
\text { Potard } \\
\text { Sélecteur }\end{array}$ & $\begin{array}{l}\text { Amplifier } \\
\text { Winding } \\
\text { Humbucker } \\
\text { Pickup } \\
\text { Pedal } \\
\text { Polepiece } \\
\text { Knob } \\
\text { Selector }\end{array}$ \\
\hline $\begin{array}{l}\text { Équipement } \\
\text { "Equipment" }\end{array}$ & $\begin{array}{l}\text { Accastillage } \\
\text { Attache de } \\
\text { courroie } \\
\text { Capo } \\
\text { Chevalet } \\
\text { Cordier } \\
\text { Médiator } \\
\text { Vibrato }\end{array}$ & $\begin{array}{l}\text { Hardware } \\
\text { Strap button } \\
\text { Capo } \\
\text { Bridge } \\
\text { Tailpiece } \\
\text { Pick } \\
\text { Vibrato }\end{array}$ \\
\hline $\begin{array}{l}\text { Manche } \\
\text { "Neck" }\end{array}$ & $\begin{array}{l}\text { Barrette } \\
\text { En D } \\
\text { Frette } \\
\text { Manche } \\
\text { Sillet (de tête) } \\
\text { Touche }\end{array}$ & $\begin{array}{l}\text { Fret } \\
\text { D-shape } \\
\text { Fret } \\
\text { Neck } \\
\text { Nut } \\
\text { Fingerboard }\end{array}$ \\
\hline
\end{tabular}

${ }^{1}$ In the field of instrument making, the word diapason/"scale" is referring to the vibrating length of the string, and not to the tuning fork (used by musician to tune their instrument). In this context, the word échelle is an anglicism of "scale" and means the same thing.

of touch. Guitarist C2P5 associates the sense of touch with the finger sensation on the string and the fingerboard in the following quote.

Ça dépend ce qu'on met derrière le toucher, après c'est vraiment la sensation physique au niveau des doigts, et euh il y a plein de choses qui rentrent làdedans, voilà le type de cordes utilisées, l'action, les frettes, dans une moindre mesure le bois de la touche, mais ça je ne suis pas très sensible à ça. Enfin sinon c'est entre une touche vernie et une touche non vernie. La sensation est différente.

"It depends on what you put behind the touch, then it is really the physical feeling in the fingers, and uh there's a lot of things that go into it, like the type of strings used, the action, the frets, to a lesser extent the wood of the fingerboard, but I'm not very sensitive to that. Otherwise it is between a varnished and an unvarnished fingerboard. The sensation is different."

(C2P5, TOUCH)

The description of sensations with guitar parts helps to assess the link with touch, as the guitar part is in contact with the player.

\subsubsection{Brand and model}

In the corpus, some guitar models or brands are mentioned. It is a good indicator to identify whether the musician is speaking about the guitar, his relation to the instrument or his feeling/experience of it, as in the following example.

C'est le toucher en général, c'est difficile à exprimer, la sensation qu'on a au vibré d'une note, au vibrato main gauche, l'impression qu'il faut y aller plus fort sur ce type de guitares, que sur ma Ibanez par exemple, où je vais tout doux et cela sonne.

"It is the touch in general, it is difficult to express, the feeling that we have when a note is vibrated, with left hand vibrato, the impression that we have to go harder on this kind of guitar, than on my Ibanez for example, where I go very soft and it sounds."

(C1P1, VIBRATION)

\subsection{Linguistic features}

\subsubsection{Personal marks}

Personal marks are the personal and possessive pronouns, as presented in Table 5. They are useful to determine the qualified object, as subject or object of verbs, and the implication in discourse, to qualify the involvement of the speaker. The use of first person singular pronouns as subject of verbs may indicate a description centered on the musician (or on the interaction between musician and instrument) and a discourse based on the ISE or the GOP, like in the example below:

Je me demande si mon premier ressenti qui était que celle-là était plus brillante, si ce n'est pas juste qu'elle est un poil plus creusée ou en tout cas qu'il se passe un peu moins de choses plus bas. Alors que sur celle-ci il se passerait plus de choses...

"I wonder if my first feeling which was that this one was brighter, if it is not just that it is a bit hollower 
Table 5. Personal marks in the corpus in French by the kind of subjects, with a proposition of English translation.

\begin{tabular}{|c|c|c|}
\hline People & Personal marks & English translation \\
\hline Speaker & $\begin{array}{l}\text { Je, moi } \\
\text { Mon, ma, mes, } \\
\text { mien(s), mienne(s) } \\
\text { Nous }\end{array}$ & $\begin{array}{l}\text { I } \\
\text { My } \\
\text { Us, our }\end{array}$ \\
\hline $\begin{array}{l}\text { Contact } \\
\text { person, } \\
\text { experimenter }\end{array}$ & $\begin{array}{l}\text { Tu, toi, vous } \\
\text { Ton, ta, tes, } \\
\text { tien }(s), \text { tienne(s), } \\
\text { vôtre, vos }\end{array}$ & $\begin{array}{l}\text { You } \\
\text { Your(s) }\end{array}$ \\
\hline Any other person & $\begin{array}{l}\text { Il, lui } \\
\text { Elle, la } \\
\text { On } \\
\text { Son, sa, ses, sien(s), } \\
\text { sienne(s) } \\
\text { Ils, elles, eux } \\
\text { Ceux, } \\
\text { Leur(s) } \\
\text { Gens, } \\
\text { Bonhomme } \\
\text { Mec, type } \\
\text { Musicien(s) } \\
\text { Personne(s) } \\
\text { Luthier(s) } \\
\text { Guitariste(s) } \\
\text { Anglo-saxons }\end{array}$ & $\begin{array}{l}\text { He } \\
\text { She } \\
\text { We, one } \\
\text { His, her } \\
\text { They } \\
\text { Those } \\
\text { Their } \\
\text { People } \\
\text { Man } \\
\text { Guy } \\
\text { Musician(s) } \\
\text { Person(s) } \\
\text { Luthier(s) } \\
\text { Guitarist(s) } \\
\text { Anglo-Saxons }\end{array}$ \\
\hline
\end{tabular}

or in any case that a little less is happening more low. While on this one more things would happen..."

(C1P5, FEELING)

In the example above, the implication in discourse relates to an ISE because the guitarist offers a reflection based on his feeling during the test.

The use of the second person pronoun brings a collective dimension, reflecting some shared knowledge between the speaker and his interlocutor. It could also indicate authority argument and doxa.

Et à chaque fois qu'tu rejoues, la guitare elle te donne la même réponse. Parce que c'est un truc qu'est hyper-fidèle, hein, à c'niveau-là .

"And every time you play again, the guitar gives you the same response. Because it is something that is greatly faithful, eh, at this level."

(C2P6, RESPONSE)

The use of authority argument and doxa is often present when the third person is used as subject of the verbs, like the impersonal form on/"we, one". In French, on can refer with high variability to a defined collective, a restricted collective (on: you and me, on: we guitarists, on: we humans, on: the others...). In the following example, on a priori refers to the whole community of guitarists, and the impersonal aspect is enhanced by the use of il ne faut pas/"you must not".

Si c'est trop flatteur, c'est que cela fait quelque chose de trop confortable à l'oreille, et du coup, on n'entend pas tout ce qu'on veut entendre, et c'est à double tranchant, il ne faut pas que cela soit trop joli non plus.

"If it's too flattering, it's because it makes something too comfortable for the ear, and therefore, one doesn't hear everything one wants to hear, and it's doubleedged, you must not let it be too pretty either."

(C1P2, COMFORT)

\subsubsection{Modal words}

Modal words ${ }^{12}$ express the degree of certainty and the degree of possibility. In the example below, the use of en général/"in general" coupled with the first person singular and quantification of appreciation j'aime pas trop/"I don't really like" helps to class the utterance under the "generalization of practices" label for the implication in discourse. The modulation by the expression of doubt or uncertainty can be used as proof of a personal judgement. And in the following example, the use of en général/"in general" expresses a usual fact, a usual situation. However, the use of justement/"in fact" is ambiguous because this word is employed as the situation is considered as evident for the interlocutor.

Alors dynamique d'une guitare, et en général la dynamique en général, pour moi, c'est le fait que y a une différence énorme entre quand j'attaque et quand j'attaque pas. Y a un truc que $\boldsymbol{j}$ 'aime pas trop c'est les guitares actives qui justement n'ont pas de dynamique.

"So the dynamics of a guitar, and the dynamics in general, for me is the fact that there's a huge difference between when I attack and when I don't. There's one thing I don't really like, it is active guitars in fact that don't have dynamics."

(C2P4, DYNAMiCS)

Moreover, a high presence of modal words in an utterance can help to class the utterance in the ISE label, like in the example below. The modal word indicates the level of certainty of the musician, and specifies the personal characteristics of his reflection. Here, in the following example, coupled with present tense and the description of a guitar of the test, the presence of modal words strengthens the personal aspect of the discourse.

Là j'ai l'impression peut-être d'une guitare qui est relativement rigide, qui a peu de, sur laquelle on a peu d'impact en terme de dynamique de jeu. Donc qu'on joue comme ça ou qu'on joue comme ça le spectre est quasiment le même en fait. Il $n$ y a pas beaucoup d'expressivité.

"Here I have the impression maybe of a guitar which is relatively rigid, which has little, on which one has little impact in terms of playing dynamics. So whether we play like this or play like that the

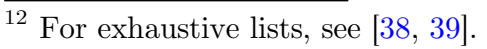


spectrum is actually almost the same. There is not a lot of expressiveness."

(C2P2, DYNAMICS)

\subsubsection{Metadiscourse}

Words or groups of words classified as metadiscourse ${ }^{13}$ are used to reformulate an idea or a concept, in order to give a more detailed information or make sure that the discourse of the participant is well understood by the experimenter. It indicates reflexivity. The presence of metadiscourse can anchor the discourse in the present tense and reality, like the example below:

La sensation comme ça que j'ai avec cet instrument, la réponse qu'il me donne, n'est pas assez intéressante mais il y a une réponse quand même en quelque sorte. Là, la réponse est encore moins bordélique je dirais mais du coup cela me fait une base où je suis assez libre, où je n'ai pas les mêmes rapports. Cet instrument me pose plus de problèmes en quelque sorte.

"The feeling like that I have with this instrument, the response it gives me, is not interesting enough but there is a response somehow. There, the response is even less messy I would say but suddenly it gives me a base where I am quite free, where I do not have the same relationships. This instrument gives me more problems somehow."

(C1P7, RESPONSE)

\subsection{Synthesis}

As a synthesis on the linguistic features of the Section 2, we present in Table 6 the features used to conclude on each parameter (relationship with the sense of touch, qualified object, implication in discourse) for each utterance.

We focused our analysis on the morpho-syntactic context (restricted context) whenever it was possible to guarantee the highest repeatability of this work and to have a systematic approach. The morpho-syntactic context was useful to identify the qualified object for each category and often the relationship with the sense of touch, but the larger context of one full sentence (intermediate context) was needed for the implication in discourse. The global utterance context (wide context) helps to resolve the cases left "undefined" by the analysis of the relationship with the sense of touch at a smaller scale with the morphosyntactic context, but tends to homogenize the results on qualified object and does not illustrate the differences between each category. Moreover, analysis of the global utterance context adds complexity for the implication in discourse with combinations of the different labels, which makes the analysis difficult, since the aim of this work is to propose a repeatable and usable method for researchers.

$\overline{{ }^{13} \text { For exhaustive lists, see }}[40,41]$.
Table 6. Observed parameters (relationship with the sense of touch abbr. Touch, qualified object abbr. Qo., and implication in discourse abbr. Id.) and helpful linguistic features.

\begin{tabular}{lccc}
\hline Linguistic features & Touch & Qo. & Id. \\
\hline Context: & & & \\
$\quad$ Morpho-syntactic & $\mathrm{X}$ & $\mathrm{X}$ & . \\
Sentence & $\mathrm{X}$ & $\mathrm{X}$ & $\mathrm{X}$ \\
$\quad$ Global utterance & $\mathrm{X}$ & $\cdot$ & . \\
\hline Association with: & & & \\
$\quad$ Body parts & $\mathrm{X}$ & $\mathrm{X}$ &. \\
$\quad$ Guitar parts & $\mathrm{X}$ & $\mathrm{X}$ & $\mathrm{X}$ \\
$\quad$ Guitar model or brand & $\cdot$ & $\mathrm{X}$ & $\mathrm{X}$ \\
\hline Personal marks &. & $\mathrm{X}$ & $\mathrm{X}$ \\
Modal words & $\cdot$ & $\cdot$ & $\mathrm{X}$ \\
Meta-discourse &. &. & $\mathrm{X}$ \\
\hline
\end{tabular}

The association with human body parts, guitar parts and guitar model is very useful to identify the qualified object. The mention of guitar parts helps to identify contact area between the guitarist and the instrument and a potential link with the sense of touch. Regarding the implication in discourse, the occurrences of guitar parts, model or brand give information if the guitarist is talking about the guitar of the present test or another guitar he once tested (or not).

Finally, linguistic features like personal marks can help to define the qualified object in utterance, and to specify the degree of implication of the guitarist (depends especially on the use of the first, the second or the third person): is the speaker referring to himself, to the guitar, to the sound? The use of modal words and meta-discourse gives information about the level of knowledge of participants, the degree of confidence of affirmation and the personal or impersonal aspects of implication in discourse.

\section{Results}

In this section, the relationship with the sense of touch is presented for both word categories and guitar parts. Then, the results on qualified object and on implication in discourse for each category are commented.

\subsection{Relationship between word categories and the sense of touch}

Thanks to the linguistic features identified in Section 3, we categorized the utterances of the corpus into the three labels presented in Section 2, and observed the following distribution:

- Yes: (utterance related to the sense of touch) $41.3 \%$ of the utterances of the corpus.

- No: (utterance not related to the sense of touch) $55.7 \%$ of the utterances of the corpus.

- Undefined: (the available information was not sufficient to conclude on the relationship with the sense of touch) $3.0 \%$ of the utterances of the corpus. 


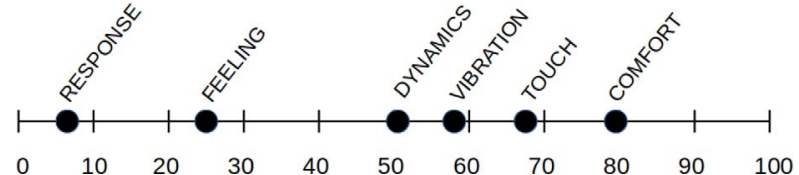

Figure 1. Percentage of utterances in relationship with the sense of touch for each category.

Even if the chosen categories were a priori related to the sense of touch (see Sect. 2.2), only $41.3 \%$ of the utterances in the corpus actually relate to the sense of touch. Figure 1 shows the proportion of utterances with a relationship with the sense of touch for each category. RESPONSE and FEELING are poorly linked to touch (respectively $8 \%$ and $25 \%$ ), due to their more general meaning, and a context more attached to sound than the other categories. The category COMFORT is mostly linked to the sense of touch with $80 \%$ of its utterances, TOUCH and VIBRATION are essentially linked to touch but the nature of words (verb or noun) affects the results (detailed in Sect. 5). In the category TOUCH, the utterances classified "no" for the relationship with the sense of touch always contain the verb toucher/"to touch", potentially because this word is used in our corpus with the meaning of the verb "to move" (or "to manipulate"). The nominal form toucher/"touch" is always used in utterances linked to the sense of touch. In the category viBRATION, the use of the verb vibrer/"vibrate" is more linked to the sense of touch than nominal forms, vibration(s)/"vibration(s), vibrato/"vibrato" and vibré/"vibrato". DYNAMICS is often used in relationship with the sense of touch (51\%), but this relationship depends on context, when associated with verbs linked to the auditory feedback (sonner/"to sound", entendre/"to hear") or specific description of pickups.

\subsection{Guitar parts and relationship with touch}

The analysis of the relationship between the word categories we higlighted in our corpus and the sense of touch is facilitated by the presence of guitar parts (detailed in Tab. 4) in utterances. In Table 7, the number of utterances mentioning guitar parts are detailed by group of guitar parts. On the 173 utterances with guitar parts, it appears that the groups "neck", "string", and "electronics" are often used in the corpus. "Neck" is employed in utterances of COMFORT and TOUCH, but "string" is often employed with the category VIBRATION. For the categories DYNAMICS, RESPONSE and FEELING, the most used group of guitar parts is "electronics".

Figure 2 shows the proportion of utterances with relationship with the sense of touch when associated with each group of guitar parts. The "neck" group is mostly linked to the sense of touch, $91 \%$ of the utterances including a guitar part of the group "neck" are linked to the sense of touch. At the opposite, the group "electronics" is rarely used linked to the sense of touch (15\%) and mainly used to only speak about the sound of the guitar (e.g. how the pickups affect the sound and description of the interaction between the pickups and the strings). The other groups, "equipment", "wood", "string" and "body", are often used in utter- ance in relationship with the sense of touch (between $50 \%$ and $67 \%$ ).

These results confirm the idea that vibrations and vibratory feedback are felt by guitar players more through the neck and the contact with the left hand than the other guitar parts, especially the group "electronics" that describes the sound transmission to the amplifier.

\subsection{Relationship between word categories and their qualified object}

The following results on the qualified object are led by the analysis of morpho-syntactic context. The detailed results for each category is shown in Figure 3, summarized in Table 8 with the one or two main qualified objects for each category.

COMFORT utterances often deal with interaction between musician and instrument whereas FEELING utterances describe the musician, and the other categories are mainly used as descriptors of the instruments. RESPONSE utterances most often describe the sound of the guitar, with occurrences based on the frequency response of the instrument. TOUCH and VIBRATION utterances are used in order to describe the guitar as a physical object, respectively for the contact of the hands with the instrument and for the vibrations of the strings. DYNAMICS is used for general descriptions of the guitar, often in association with the pickups of the guitar.

As an extension of these results, it can be noted that categories mostly linked to touch (80\% for COMFORT, $68 \%$ for TOUCH, and $58 \%$ for VIBRATION) are descriptors of the guitar as an object (or the interaction between the musician and his instrument).

\subsection{Relationship between word categories and the implication in discourse}

The analysis of the implication in discourse reveals a majority of utterances describing personal experience (ISE and GOP). Details are presented in Figure 4. For each category we could observe that less than $20 \%$ of its utterances refer to doxa (the least personal kind of implication in discourse). It confirms that the corpus mostly contains utterances with the personal point of view of guitarists, due to the playing situation in the perceptual tests and also to the interview guides that were on purpose focused on personal experience.

The ISE is the most common kind of implication in discourse found for each category of words, except for VIBRATION, where most of utterances concern a less immediate, related to present task, experience, namely GOP. The proportion of doxa in the corpus is low, but one can observe more doxa for the categories RESPONSE, TOUCH, VIBRATION. For instance, COMFORT, DYNAMICS and FEELING may be more appropriate to speak about and focus on personal experience. The implication in discourse varies with the nature of words (verb or noun), with important variations for VIBRATION, TOUCH, FEELING and COMFORT, as detailed in Section 5 . 
Table 7. Number of utterances (abbr. \#utt.) for each group of guitar parts in the corpus.

\begin{tabular}{lc}
\hline Label of the group & $\#$ utt. \\
\hline Bois/"Wood" & 35 \\
Corde/"String" & 67 \\
Corps/"Body" & 25 \\
Électronique/"Electronics" & 53 \\
Équipement/"Equipment" & 16 \\
Manche/"Neck" & 58 \\
\hline
\end{tabular}

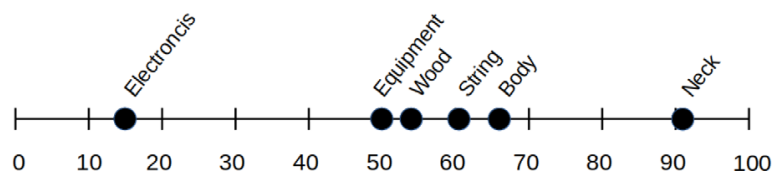

Figure 2. Percentage of utterances in relationship with the sense of touch by guitar parts group.



Figure 3. Percentage of each qualified object for each category of words: musician, interaction, guitar (abbr. g.) as sound, g. as object, g. in general.

Table 8. Distribution of the qualified object in utterances for each category (qualified object for each category with more than $25 \%$ of utterances of the category).

\begin{tabular}{llc}
\hline $\begin{array}{l}\text { Label of the } \\
\text { category }\end{array}$ & $\begin{array}{l}\text { Qualified } \\
\text { object }\end{array}$ & $\begin{array}{c}\text { Percentage of } \\
\text { utterances }\end{array}$ \\
\hline COMFORT & Interaction & 41.2 \\
G. as object & 29.4 \\
\hline DYNAMICS & G. in general & 68.6 \\
\hline RESPONSE & G. as sound & 45.3 \\
\hline FEELING & G. in general & 30.2 \\
\hline TOUCH & Musician & 64.2 \\
& G. as sound & 26.4 \\
\hline VIBRATION & G. as object & 35.3 \\
\hline
\end{tabular}

In the analysis of the corpus, there are few links between the relationship with the sense of touch and implication in discourse, as presented in Table 9. The main result is a higher proportion of utterances with doxa that have no

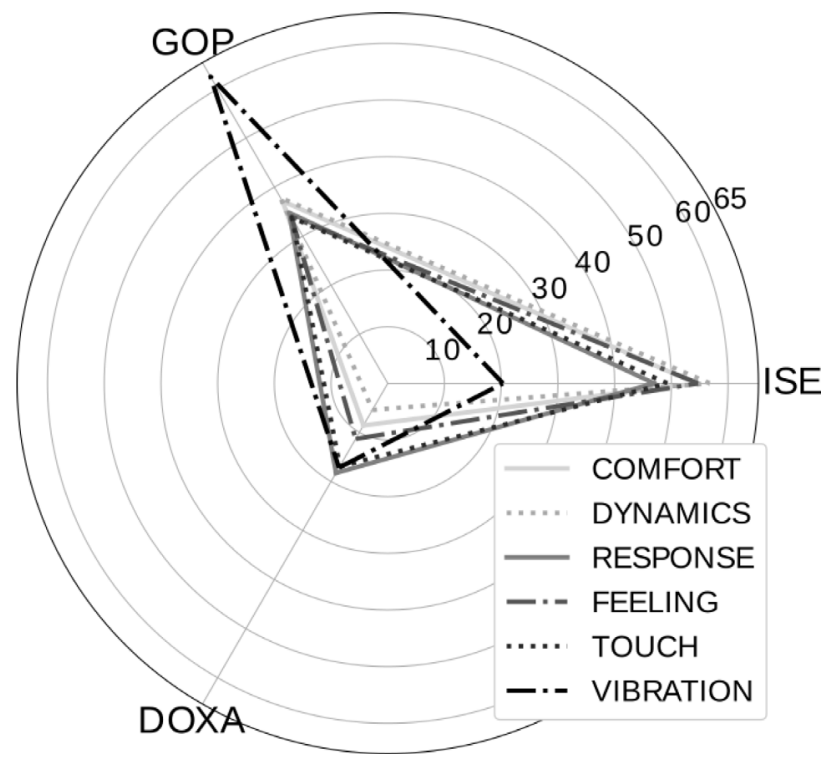

Figure 4. Percentage of different implication in discourse for each category, with the analysis on sentence context. ISE corresponds to immediate sensory experience, GOP corresponds to generalization of practices, and DOXA corresponds to doxa.

Table 9. Relationship with the sense of touch of utterances by implication in discourse, in percentage. ISE corresponds to immediate sensory experience, GOP corresponds to generalization of practices, and DOXA corresponds to doxa.

\begin{tabular}{lccc}
\hline Category & Yes $(\%)$ & No $(\%)$ & Undefined $(\%)$ \\
\hline ISE & 42.1 & 54.4 & 3.5 \\
GOP & 47.0 & 50.3 & 2.7 \\
DOXA & 27.3 & 69.1 & 3.6 \\
\hline
\end{tabular}

relationship with the sense of touch in comparison with utterances with ISE and GOP. In fact, the utterances classified "doxa" are often related to sound and auditory feedback. The reflection about sound may be considered by the musician as perceptible by the interlocutor and quite obvious (the sound is perceived by both the musician and the spectator, or here the researcher). But the vibratory signal is felt by the musician only, who must explain to his interlocutor the perceived vibrations.

\section{Discussion}

As the linguistic analysis showed, there are several linguistic features usable to identify the relation of each chosen category with the sense of touch. However, the results do not permit to assess a permanent relationship, but provide trends. This section discusses these results and gives details about the variability between words within some of the categories of words under study.

If COMFORT is mainly linked to the sense of touch $(80 \%$ of utterances present a relationship with the sense of touch) with low variability between words, TOUCH and viBRATION 
highly depend on the nature (verb or noun) of words used, as mentioned in Section 4.1. The category TOUCH, when the word is the noun "touch", is always in relationship with the sense of touch, whereas when the word used is the verb "to touch" the relationship with touch is much more rare $(24 \%)$. This difference is explained by the use of the verb "to touch" by guitarists when playing, as they were asking (during test) permission to touch knobs or settings on the guitar or the amplifier. For example in this quote:

Ce qui est difficile, c'est de ne pas pouvoir toucher les boutons. C'est certain que je ne serais pas resté droit.

"The hard part is not being able to touch the knobs. Certainly I would not have stayed like this [all knobs at mid values]."

(C1P5, TOUCH)

For viBRAtion, the opposite trend is observed. The use of nouns ("vibration", "vibrato") is linked to the sense of touch in $47 \%$ of utterances, whereas the use of the verb ("vibrate") is linked to the sense of touch in $71 \%$ of utterances. The verb is often used to describe how the instrument vibrates and how it is felt by the musician:

Pour moi, il est certain que les sensations que j'ai dans les doigts au toucher dans la manière dont vibre l'instrument, la sensation charnelle à l'instrument sont complètement reliées au son.

"For me, it is certain that the sensations I have in my fingers through touch in the way the instrument vibrates, the carnal sensation to the instrument are completely related to the sound."

(C1P10, viBration)

The category DYNAMICS presents a variability in the relationship with the sense of touch. Contrary to TOUCH and VIBRATION, this variability is not due to the different forms of the words in this category. We mainly found the noun dynamique/"dynamics" in the corpus (note that there was only one use of the adjective dynamique/"dynamic" in the corpus). The difficulty of the variability in the relationship with the sense of touch could be solved by the observation of occurrences of human body parts and action verbs:

Pour jouer rock mais j'ai beaucoup plus de dynamique au doigt. Et pour des phrases hard rock jusqu'au blues jazz, je passe de l'un à l'autre.

"To play rock music but I have a lot more dynamics on my finger. And for hard rock to blues jazz phrases, I switch from one to the other."

(C1P4, DYNAMICS)

The variability on the nature of words used is less important for RESPONSE and FEELING, as they have no relationship with touch in most of the cases. RESPONSE does not present high variability through the observed parameters (relationship with touch, qualified object and implica- tion in discourse), but the implication in discourse for the category FEELING is often ISE when the verbal form is used (ISE $59.5 \%$, GOP $28.6 \%$, and doxa $11.9 \%$ ), and often GOP when the nominal form is used (ISE $36.4 \%$, GOP $54.5 \%$, and doxa 9.1\%).

\section{Conclusion}

This study provides answers to the questions raised in Section 1. The six chosen categories of words (COMFORT, DYNAMICS, RESPONSE, FEELING, TOUCH and VIBRATION) were analyzed through three parameters. First, the link with the sense of touch was determined, in order to check the usability of those words to speak about touch. Second, the specific qualified object of each category was specified, in order to check the assumption of the literature (i.e. the chosen words were considered to be descriptors of the relation between the instrument and the musician). Third, the implication in discourse of guitarists when using the chosen words is analyzed in order to identify the degree of personal implication. A linguistic analysis was done, based on different features (presented in Sect. 3): nature of the words, personal marks, morpho-syntactic context, modal words, meta-discourse, reference to guitar parts, reference to human body parts.

For the relationship with the sense of touch, a high variability between the category of words is observed, and even between words in a category. The four categories COMFORT, DYNAMICS, TOUCH and VIBRATION are linked with the sense of touch. It is important to keep a special attention to the nature of words for TOUCH with the use of the noun and VIBRATION with the use of the verb. For electric guitarists in playing situation in our corpus, the verb toucher/ "touch" is not related to the sense of touch, with a meaning close to "move" more than "touch", and the nouns vibration/ "vibration", vibrato/"vibrato" and vibré/"vibrato" are less linked to the sense of touch than the verb vibrer/"vibrate". The category COMFORT, as descriptor of the relation between the instrument and the musician, is highly linked to the sense of touch. DYNAMICs can be used to speak about touch, but the context of its use must be taken into account, especially when associated with a description of the pickups or verbs of the auditory feedback (e.g. sound or hear). The four categories COMFORT, DYNAMICS, TOUCH and VIBRATION can be used in further works to elaborate a survey on touch, and they will be useful to analyze the relationship with the sense of touch on further perceptual tests. However, the categories RESPONSE and FEELING have no strong link with the sense of touch, but can be useful as they are more employed by guitarists than the words in the other categories, and can be interesting to target and incite a discourse focused on the musician or the guitar.

The sense of touch was studied in utterances of the corpus that include references to electric guitar parts. It was shown a strong link of the group "neck" with the sense of touch, more than the other electric guitar parts. As the electric guitar players feel more vibrations on this part of the electric guitar than the others, it seems to be very interest- 
ing to measure the vibratory behavior of the electric guitar, and link the vibrotactile perception with the physical vibration (Fleischer proved a higher mobility at the neck of the guitar in [10]; Paté et al. underlined the role of the conductance of the neck to predict decay time of a tone [42]).

Moreover, for the development of questions and questionnaires for perceptual tests in playing situations, the focus on these contact areas could permit to orient the discourse on the sense of touch, and can be coupled with the categories linked to the sense of touch.

The analysis of the implication in discourse illustrates the personal implication of guitarists when both freely playing and speaking. The chosen categories are related to the ISE, except VIBRATION which is related to GOP. It could be due to the need for comparison when guitarists speak about how the guitar vibrates, because only the musician can access the vibratory feedback of the instrument. In order to be understood by the experimenter, he has to explain his feelings using comparisons with other situations. A potential lack of words to speak about the sense of touch could explain this need.

This work could be a basis for further works on vibrotactile perception and discourse on perceived vibrations, linked to the feeling of sound (when assumed that the auditory feedback and the vibratory feedback are both present for the musician when he is playing). The words presented through the different categories can now be used with a higher level of knowledge and some of them permit to target the vibrotactile perception. Tests may now be conducted in different formats (playing tests, interviews, surveys, physical studies) with the use of the word categories described in this article, which help to focus on vibrotactile perception.

\section{Conflict of interest}

The authors declare that they have no conflicts of interest in relation to this article.

\section{References}

1. C. Saitis, B.L. Giordano, C. Fritz, G.P. Scavone: Perceptual evaluation of violins: A quantitative analysis of preference judgments by experienced players. The Journal of the Acoustical Society of America 132 (2012) 4002-4012.

2. B. Navarret: Caractériser la guitare électrique : définitions, organologie et analyse de données verbales. $\mathrm{PhD}$ thesis, Paris 8, 2013.

3. A. Paté: Lutherie de la guitare électrique solid body: aspects mécaniques et perceptifs. $\mathrm{PhD}$ thesis, UPMC, 2014

4. A. Paté, J.-L. Le Carrou, B. Navarret, D. Dubois, B. Fabre: Influence of the electric guitar's fingerboard wood on guitarists' perception. Acta Acustica united with Acustica 101 (2015) 347-359.

5. I. Wollman, C. Fritz, J. Poitevineau, S. McAdams: Investigating the role of auditory and tactile modalities in violin quality evaluation. PLoS One 9 (2014) e112552

6. C. Saitis, H. Järveläinen, C. Fritz: The role of haptic cues in musical instrument quality perception. In: S. Papetti, C. Saitis, Eds. Musical haptics, Springer International Publishing, 2018, pp. 73-93.
7. M.T. Marshall, M.M. Wanderley: Vibrotactile feedback in digital musical instruments. In: NIME 06, Paris, France, 2006.

8. G. Bissinger, D. Oliver: 3-D laser vibrometry on legendary old Italian violins. Sound and Vibration 41 (2007) 10-15.

9. J.-L. Le Carrou, A. Paté, B. Chomette: Influence of the player on the dynamics of the electric guitar. The Journal of the Acoustical Society of America 146 (2019) 3123-3130.

10. H. Fleischer: Vibration of an electric bass guitar. Acta Acustica united with Acustica 91 (2005) 247-260.

11. H. Fleischer, T. Zwicker: Mechanical vibrations of electric guitars. Acta Acustica united with Acustica 84 (1998) 758-765.

12. F. Fontana, S. Papetti, H. Järveläinen, F. Avanzini: Detection of keyboard vibrations and effects on perceived piano quality. The Journal of the Acoustical Society of America 142 (2017) 2953-2967.

13. W. Goebl, R. Bresin, I. Fujinaga: Perception of touch quality in piano tones. The Journal of the Acoustical Society of America 136 (2014) 2839-2850.

14. F. Fontana, S. Papetti, H. Jarvelainen, F. Avanzini, B.L. Giordano: Perception of vibrotactile cues in musical performance. In: S. Papetti, C. Saitis, Eds. Musical haptics, Springer International Publishing, 2018, pp. 49-72.

15. M. Giordano, M.M. Wanderley: Measuring the haptic behavior of an acoustic guitar as perceived by the player by means of a vibrating actuator. The Journal of the Acoustical Society of America 133 (2013) 3233-3233.

16. I. Wollman: Perception Bimodale des violonistes en situation de jeu : Influence des retours auditif et vibrotactile sur l'evaluation du violon. $\mathrm{PhD}$ thesis, Paris 6, 2013.

17. I. Wollman, C. Fritz, J. Poitevineau: Influence of vibrotactile feedback on some perceptual features of violins. The Journal of the Acoustical Society of America 136 (2014) 910-921.

18. A. Mamou-Mani, L. Placido, D. Sharp: Physical and perceptual differences between two trumpets of the same model type. In: Société Française d'Acoustique, Ed. Proceedings of the Acoustics 2012 Nantes Conference, Nantes, France, 2012, pp. 2689-2694.

19. J.J. Gibson: The Concept of the Stimulus in Psychology. The American Psychologist (1960) 694-703.

20. C. Fritz, D. Dubois: Perceptual evaluation of musical instruments: State of the art and methodology. Acta Acustica united with Acustica 101 (2015) 369-381.

21. C. Fritz, A. Muslewski, D. Dubois: A situated and cognitive approach of violin quality. In: Proceedings of 20th International Symposium on Music Acoustics, 2010.

22. C. Guastavino: Exploring soundscapes. In: D. Dubois, C. Cance, M. Coler, A. Paté, Eds. Sensory experiences: Exploring meaning and the senses, John Benjamins Publishing, 2021, pp. 139-167.

23. C. Guastavino: Validité écologique des dispositifs expérimentaux. In: D. Dubois, Ed. Le sentir et le dire, L'Harmattan, 2009, pp. 233-252.

24. D. Dubois, C. Cance, M. Coler, A. Paté: Empirical considerations for questioning sensory experience. In: Sensory experiences: Exploring meaning and the senses, John Benjamins Publishing, 2021, chap. 10, pp. 371-401.

25. C. Cance, D. Dubois, A. Paté, M. Coler: From stimulation to stimuli construction and selection. In: D. Dubois, C. Cance, M. Coler, A. Paté, Eds. Sensory experiences: Exploring meaning and the senses, John Benjamins Publishing, 2021, chap. 12 , pp. $440-473$.

26. V. Alluri, P. Toiviainen: Exploring perceptual and acoustical correlates of polyphonic timbre. Music Perception 27 (2010) 223-242. 
27. M. Barthet, P. Guillemain, R. Kronland-Martinet, S. Ystad: From clarinet control to timbre perception. Acta Acustica united with Acustica 96 (2010) 678-689.

28. C. Fritz, A.F. Blackwell, I. Cross, B.C.J. Moore, J. Woodhouse: Investigating English violin timbre descriptors. In: K. Miyazaki, Y. Hiraga, M. Adachi, Y. Nakajima, M. Tsuzaki, Eds. Proceedings of the 10th International Conference on Music Perception \& Cognition (ICMPC 10), 2008, pp. 638-641.

29. C. Fritz, A.F. Blackwell, I. Cross, J. Woodhouse, B.C.J. Moore, Exploring violin sound quality: Investigating English timbre descriptors and correlating resynthesized acoustical modifications with perceptual properties. The Journal of the Acoustical Society of America 131 (2012) 783-794.

30. M. Lavoie: Conceptualisation et communication des nuances de timbre à la guitare classique. $\mathrm{PhD}$ thesis, Université de Montréal (2013).

31. L.N. Solomon: Semantic approach to the perception of complex sounds. The Journal of the Acoustical Society of America 30 (1958) 421-425.

32. M. Bernays, C. Traube: Verbal expression of piano timbre: Multidimensional semantic space of adjectival descriptors. In: International Symposium on Performance Science, 2011, pp. 299-304.

33. A. Zacharakis, K. Pastiadis, G. Papadelis, J.D. Reiss: An investigation of musical timbre: Uncovering salient semantic descriptors and perceptual dimensions. In: Proceedings of the 12th International Society for Music Information Retrieval Conference (ISMIR 2011), 2011, pp. 807-812.

34. A. Paté, J.-L. Le Carrou, B. Navarret, D. Dubois, B. Fabre: A vibro-acoustical and perceptive study of the neck-to-body junction of a solid-body electric guitar. In: Proceedings of the Acoustics 2012 Nantes Conference, Nantes, France, 2012, pp. 2717-2722.

35. B. Verine: Le vocabulaire tactile existe, je l'ai entendu. In: Sensorialité et handicap : Toucher pour apprendre, toucher pour communiquer, France, 2016.

36. P. Cambourian, A. Paté, C. Cance, B. Navarret, J. Vasseur: Investigating the vocabulary used by electric guitar players to speak about touch. E-Forum Acusticum, 2020, pp. 10291036.

37. C. Parisse: La morphosyntaxe: Qu'est ce qu'est? - Application au cas de la langue française? Rééducation Orthophonique 47 (2009) 7-20.

38. H. Nølke: Pertinence et modalisateurs d'énonciation. In: Unité de linguistique française, Ed. Cahiers de linguistique francaise, Vol. 11. Librairie Droz, 1989, pp. 105-126.

39. R. Vion: Modalisation, dialogisme et polyphonie. In: J. Bres, P.P. Haillet, S. Mellet, H. Nølke, L. Rosier, Eds. Dialogisme, polyphonie: approches linguistiques. Actes du colloque de Cerisy, Vol. 29, 2004, pp. 143-157.

40. A. Borillo. Discours ou métadiscours ? Documentation et Recherche en Linguistique Allemande Vincennes (DRLAV) 32 (1985) 47-61.

41. L. Maxim, Du métadiscours aux métaconnaissances. In: D. Dubois, Ed. Le sentir et le dire, L'Harmattan, 2009, pp. 339358.

42. A. Paté, J.-L. Le Carrou, B. Fabre: Predicting the decay time of solid body electric guitar tones. The Journal of the Acoustical Society of America 135 (2014) 3045-3055.

Cite this article as: Cambourian P. Paté A. Cance C. Navarret B. \& Vasseur J, et al. 2022. Vocabulary to speak about touch: analysis of the discourse of electric guitar players. Acta Acustica, 6, 2. 